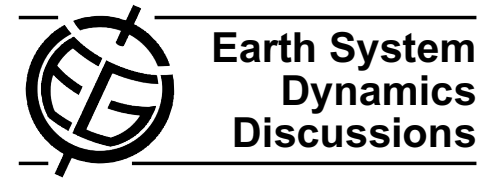

This discussion paper is/has been under review for the journal Earth System

Dynamics (ESD). Please refer to the corresponding final paper in ESD if available.

\section{Radon monitoring as a possible indicator of tectonic events}

\author{
V. I. Outkin ${ }^{1}$, I. A. Kozlova ${ }^{1}$, A. K. Yurkov ${ }^{1}$, P. K. Dutta ${ }^{2}$, O. P. Mishra ${ }^{3,4}$, and \\ M. K. Naskar ${ }^{2}$ \\ ${ }^{1}$ Institute of geophysics, Ekaterinburg, Amundsen Str. 100, 620016 Yekaterinburg, Russia \\ ${ }^{2}$ Electronics and Tele-Communication Dept. Jadavpur University, 700032 Kolkata, \\ West Bengal, India \\ ${ }^{3}$ SAARC Disaster Management Centre (SDMC), IIPA Campus, Ring Road Delhi, \\ 110002 Delhi, India \\ ${ }^{4}$ Geo-seismology Division, Geological Survey of India (CHQ), Kolkata, India
}

Received: 6 October 2012 - Accepted: 4 January 2013 - Published: 21 January 2013

Correspondence to: P. K. Dutta (ascendent1@gmail.com)

Published by Copernicus Publications on behalf of the European Geosciences Union.

\section{ESDD}

4, 93-107, 2013

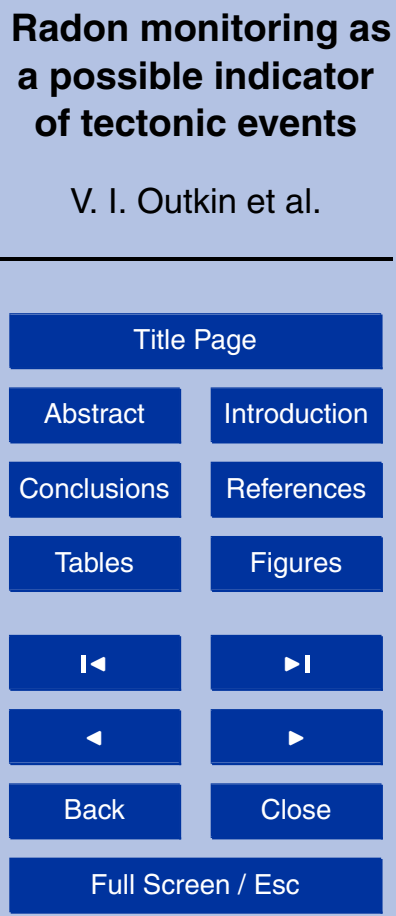

Printer-friendly Version

Interactive Discussion

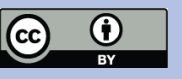




\section{Abstract}

The proposed work describes research into the behavior of radon (VAR-volume activity of radon) excreted from the array. Radon migration and its selection from the array depends on the porosity, permeability and fractures in the array. A drastic change in 5 the strength of an array and reset the elastic stresses by external forces (earthquake) occurs when certain changes in the structure of the array as the compressive and tensile strength of the array.

\section{Introduction}

Researches of last years have shown that despite of development of the seismometric 10 equipment, methods of processing of seismic signals, development of seismometric complexes etc., the problem of the forecast of tectonic earthquakes (especially shortterm) remains unsolved as passive seismological signals not always are informative in relation to preparing event while speed of occurrence of seismological signals before event depending on volume of cracked rock at depth (preparation focal zone) is considered as a primary local source of precursor signals. Seismological signals for the purposes of the short-term forecast of earthquakes is practically impossible. Several researchers have attempted earthquake prediction using radon detection techniques in different tectonic environment. The initial investigation on radon presence in ground-soil was performed at an active fault whereby anomalous radon concentrations (Imamura, 1947) were reported before the strong earthquake zone (Hatuda, 1953). This was there after followed as Tashkhent (Ulomov, 1967) which has been closely followed by a series of radon data observations as anomalies correlated with geophysical events available from different countries. Elaborate research work conducted in Japan (Hirotaka et al., 1988; Igarashi et al., 1995) with Turkey (Inceoz et al., 2006; Friedmann et al., 1988) followed by Mt. Etna, Italy since 2001 (Immè et al., 2005; Morelli et al., 2012). Precursory phenomena of radon in earthquake sequence were observed by Rastogi et al. (1987)
ESDD

4, 93-107, 2013

\section{Radon monitoring as a possible indicator of tectonic events}

V. I. Outkin et al.

\section{Title Page}

Abstract Introduction

Conclusions References

Tables Figures

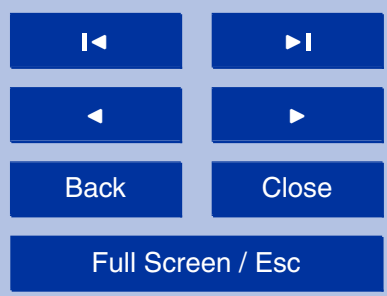

Printer-friendly Version

Interactive Discussion

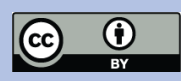


and precursory behavior of helium and radon observed for magnitude 5 earthquakes (Walia et al., 2005). Earthquake occurrence is found to be proportional to the volume of the pre-stressed lithosphere or to the energy of the earthquake. The main difference of monitor of VAR from conventional monitoring data of radon of a different type (fixed, nu-

5 merical values, for example, electrical resistivity, seismic activity, etc.) is that it is not just the amount of VAR at a given point in a given time, and changing the VAR in time. The observed time of earthquake prepare is enough to determine the nature of the behavior of the VAR (Outkin et al., 1999) and, accordingly, the nature of the deformation of the lithospheric block (stretching or compression). Several mechanisms and techniques 10 has been postulated by various investigators to explain the earthquake-related gas anomalies, most involving tectonically induced movement of crustal fluids. Active fault zones suggests that premonitory patterns and the associated earthquakes are possibly incidental results of some broad-scale episodic strain changes in the crust (King, 1986). Spatio-temporal monitoring of radon in 1970-s-1980-s of the last century (King 15 et al., 1993) in spite of these shortcomings, was the large-scale experiment of radon monitoring, the results of which have yet to be evaluated by researchers while the later monitoring measurement of VAR (Outkin and Yurkov, 1997a,b; Outkin, 1999, 2000) confirmed the fairness of the main conclusions reached after examining the radon monitoring. The observation of anomalies in the radon concentration in soil gas and ground water before earthquakes initiated systematic investigations on earthquake precursor phenomena. Radon concentration variations with changes in flow patterns of diverse fluids within the ground, resultant from modifications in local stress fields of the crust.

\section{Mechanism of radon anomaly for forecasting}

During the experiment (radon monitoring 78-81) in California 25 events with a mag25 nitude of 4.5 to 5.8 occurred. Study of VAR change charts in various locations (total 60 radon monitoring stations) in time for each event showed complete uniformity of conduct VAR in zones of compression or stretching of the array. While these data are

ESDD

4, 93-107, 2013

\section{Radon monitoring as a possible indicator of tectonic events}

V. I. Outkin et al.

\section{Title Page}

Abstract Introduction

Conclusions

Tables References Figures

14

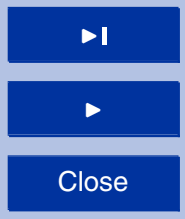

Back

Close

Full Screen / Esc

Printer-friendly Version

Interactive Discussion

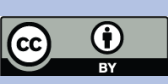


corroborated by the simultaneous measurement of conduct VAR in multiple measurement points located in the zones of compression or stretching of the array. Only during the experiment (the period of radon monitoring $78-81 \mathrm{gg}$ ). The profile of the VAR study at different points of registration (only 60 stations radon monitoring) over time for each 5 event showed complete uniformity of conduct VAR in zones of compression or stretching of the array. In this case, these data support the simultaneous measurement of the behavior of VAR measurements at several points located in areas of compression or stretching of the array. Characteristic changes in the VAR in the preparation and implementation of the earthquake are clearly visible in Fig. 1, which shows the spatial and 10 temporal changes of the VAR before the earthquake 20 January 1980 with a magnitude of 5.8. Area of compression and expansion of the array determined by the behavior of the curve in time VAR (Fig. 1, right panel). VAR behavior for zones of compression and tension in the preparation of the earthquake varies. In areas of compression is consistently reducing VAR to some small value, followed by the discharge of the stress state 15 of the array (earthquake). This is evident from the charts of the UAR for stations 43 , $46,51,52,58$ and 63 . If radon monitoring station is located in the compression zone of the array, then the change in the concentration of radon in time is an exponential curve of the form:

$I_{C}=I_{0}(\exp (-k t))$

20 where $I_{0}$ - some initial VAR intensity before its decline, which lasts from 3 to 5 months (120-150 days); $k$ - compaction ratio of the array (the name of a conditional). Compression process ends the earthquake, destruction (changing) array structure (Fig. 2). It can assume that only the structure interlock friction collapses because from experience know that lithospheric blocks remain unchanged (Rogozhin, 2002). The compression process ends earthquake destruction (change) the structure of the array. We can assume that only the structure collapses provides Interconnect friction, because experience has shown that the lithospheric blocks remain unchanged. The analysis in a mode on-line the data of radonic monitoring, allocation of zones of compression and

\section{ESDD}

4, 93-107, 2013

\section{Radon monitoring as a possible indicator of tectonic events}

V. I. Outkin et al.

\section{Title Page}

Abstract Introduction

Conclusions

Tables

References

Figures

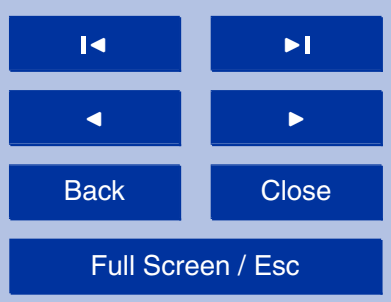

Printer-friendly Version

Interactive Discussion

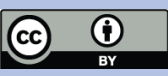


a stretching of files of researched geodynamic range; allocation of zones of a critical (prewaste) condition of a file at is intense - deformed condition. Shape of the curve changes VAR compression array and stretch in the array observed at different stations in Figs. 2 and 3 respectively differ slightly, but for all the curves is possible to distin5 guish to tell two zones for the time of the earthquake preparation and the reset voltage (actual earthquake). The last zone is characterized by the almost constant values of the United Arab Republic in time. If radon enters the station location area stretching the array, the change in the concentration of radon (VAR) is more complex (stations 43 and 46 in Fig. 1), which is well described by the following:

${ }_{10} I_{p}=I_{0} k \times t\left(e^{-k t}\right)$

where $I_{0}$ - some initial radon concentration, $k t$ - magnification radon tensile array where $k$ is the magnification range. VAR curve first increases (increase in radon concentration by stretching the array, increasing its permeability, etc.), reaches a maximum, and then reset the state of stress is observed (the possible collapse of the ar15 ray), the increase in the array and the decline of radon. Typical curves of the variation of the concentration of radon (VAR) for the various measuring stations in the expansion of the array obtained from experiments monitoring radon (Outkin et al., 1999), are shown in Fig. 3. The results presented through work gives concrete proof that the final process of preparation of a tectonic earthquake has a duration of 120-150 days 20 and is not dependent on the type of array deformation (compression or tension) reflection of the process of preparation of a tectonic earthquake in the radon concentrations (VAR) starts for 120-150 days before the event and does not depend on the type of of deformation (compression or a stretching); of the array, whereas the size of area of expected event with magnitude about 4 makes about $40 \mathrm{kms}$; events with magnitude about $50 \mathrm{kms}$ and magnitude 6 more than $50 \mathrm{kms}$. A mathematical modeling of radon concentration anomalies and geodynamical events that shows change of stressed-strained state of the environment in the preparation of the tectonic earthquake (Dutta et al., 2012a). Location window after a certain precursor is a key value
ESDD

4, 93-107, 2013

\section{Radon monitoring as a possible indicator of tectonic events}

V. I. Outkin et al.

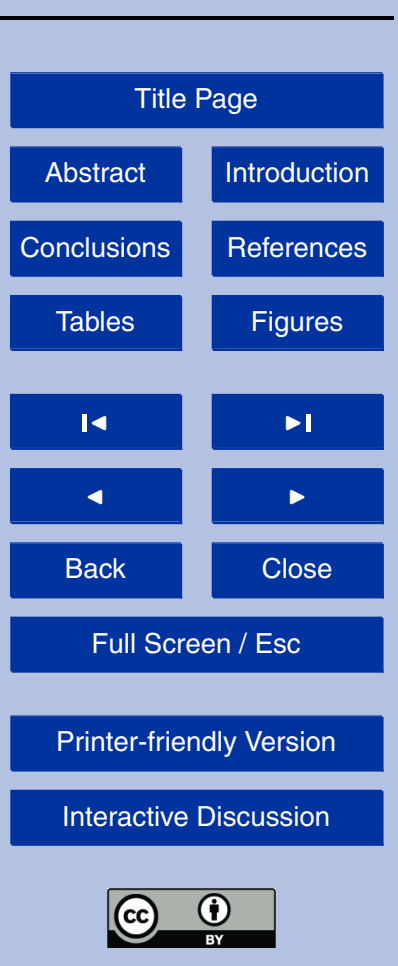


and should always be given. Perhaps this may be done by introducing a quality factor which is a function of the predicted entrance windows for the quake, the probability and the mean recurrence periods of earthquakes in the considered area. These changes are clearly in VAR curves (Figs. 2 and 3 ) received on monitoring data (Outkin and Ko5 zlova, 2000). Strain changes get amplified at the earthquake and anomaly sites with sufficient pre-existing stresses that may reach some critical levels (above half fracture strengths) for generation of the earthquakes and anomalies. Energy released in earthquakes is stored along the brittle crust at depths between the surface and $10 \mathrm{~km}$ down; judged from distribution of small earthquakes. Advent of advanced remote sensing 10 methodologies have been initiated to study pre-earthquake deformation detection. A number of researchers are engaged in analyzing relative data collected from different space-borne sensors and ground-based stations to establish a causal relationship between physical mechanisms underlying the earthquake genesis and occurrence and sources of the so-called seismoelectromagnetic emissions. Surface deformation data are provided by GPS and SAR imaging, land surface temperature changes by ASTER, Landsat TM and ETM, different types of cloud studies using MODIS and Seawifs data, electromagnetic and ionosphere anomalies by ground passive stations and radon gas emissions in the faults areas by solid on the ground detectors. Seismologists could then study in real time how strain varies in rocks to identify particular locales where a slip could be about to occur. Multispectral and multitemporal satellite images over a period can be analyzed for recognizing the continuity and local relationships of active faults as well as for geologic and seismic hazard mapping. Seismic hazard maps the regional geomorphologic maps which combine information on rock types, soil types and slopes for seismically active areas.

\section{Supportive evidence of remote sensing}

The automated information extraction and change detection from earth observation data based on ground networks of instruments in the major seismic areas of the Earth

\section{ESDD}

4, 93-107, 2013

\section{Radon monitoring as a possible indicator of tectonic events}

V. I. Outkin et al.

\section{Title Page}

Abstract Introduction

Conclusions

Tables References Figures

14

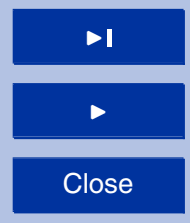

Back

Close

Printer-friendly Version

Interactive Discussion 
and Low-Earth-orbit (LEO) multi-instrument satellites, as well as laboratory and theoretical investigations important tool to understand the complexity of rock behavior, extent of deformation and amount of mineral assemblage from crystal lattice of host rock. Space observations are being performed for observing changes in ground eleva5 tions as propagating in the surrounding medium allow the earthquake precursors to be observed in a finite region of the Earth's surface (precursor area). Application of remote sensing and geo spatial analysis will provide spectral pattern changes within the rock matrix based on data gathered simultaneously and continuously by space observations and ground-based measurements based on surface deformation provided by GPS and 10 SAR imaging. Implementation of multispectral and hyperspectral remote sensing data based on gamma ray spectrometry, digital elevation models and synthetic aperture radar imagery in lithological and structural mapping dates back to the launch of the first Landsat system (Drury, 1993). Deformations get shifted in time relative to each other indicating propagation of the pre-seismic strain field from the preparation focal area 15 to the tilt sites, through the rigid blocks of the region. Prospecting for hyper-spectral imagery from space for the geodetic and electromagnetic footprints of changes in the emission of gases. Gamma ray observation system (Tsukuda, 2008) was developed to monitor helpful in long term monitoring of crustal activity. When the concentrated stresses in the rock matrix create new micro-cracks and the area and/or volume of preexisting dilatant volume of cracked rock that drives pore fluids to flow upward through crack network when a vent-like path occurs due to the change of strain leads to dislocation of mineral assemblage in the crystal lattice. This process of dislocation of mineral assemblage is associated with emanation of radon and can be well detected through remote sensing; land based sensors and customized wireless sensor instruments. Because of the associated brittle behavior of the rock matrix dislocation for the mineral assemblage in the soft surface layer taking place in association of radon emission in soft surface layer. Crustal heterogeneity of the fault beneath the sub surface causes the change in differential strain pattern to bring the tectonic events generally accompanied by radon emission from sub surface causative rock. Measurement of all satellite

\section{ESDD}

4, 93-107, 2013

\section{Radon monitoring as a possible indicator of tectonic events}

V. I. Outkin et al.

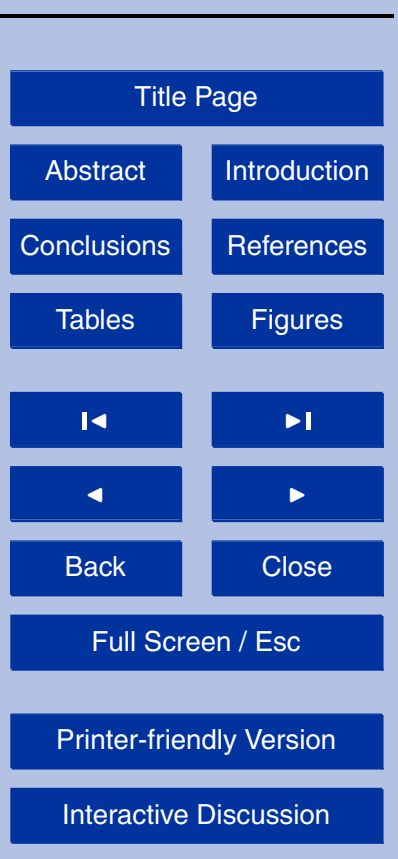


information recorded through the in the imagery of tectonic events can give supportive evidence for the onset times of rock deformation and associated phenomena.

\section{Results}

Optimum (maximum) number of stations monitoring radon, which is necessary to con5 trol the research area you can define, based on the size of the prepare area of tectonic events. This is an area with a radius of $40 \mathrm{~km}$ to earthquakes with magnitudes of about $4.50 \mathrm{~km}$ is radius for earthquakes with $M \geq 5$ and a radius of about 50 miles or more for earthquakes with $M \geq 6$. Thus, $10-12$ stations radon monitor is enough to monitor the state of lithospheric block of size 200 on $100 \mathrm{~km}$ when controlling the seismic events of magnitude 4 . To monitor events with a minimum of magnitude equal to or more than 5 it is enough 6-8 stations to landfill size 100 to $200 \mathrm{~km}$. The complex geological structure study on the number of stations may need to be increased. Obligatory condition of tectonic earthquake is the availability of the required voltage in the Earth's crust, which is called deformation lithological unit or well plates. A sufficient condition for the emergence of some can be considered as external forces that trigger reset voltage when critical levels of stressed-strained state of the array (Outkin et al., 2006). Advantages of geodynamic prior monitoring seismological monitoring consists in the following: (a) monitor of radon is placed directly in the research of radon gas block of rocks, which significantly improves the signal-to-noise ratio when recording data; (b) radon monitoring signal allows to judge about the dynamics of stressed-strained state of the block of rock (tensile-compression); (c) speed in the dynamics of processes in preparation for earthquake rocks is relatively small, which allows processing data monitoring in real time. The short-term prognosis of particularly large earthquakes is entirely based on the monitoring of the Earth's rotation: substantial "triggering function" (variations of the Earth's rotation) shed the accumulated tension over the entire surface of the Earth, causing massive earthquakes. Therefore, warning of major earthquakes must be formed on the basis of monitoring variations in Earth rotation irregularities.

\section{ESDD}

4, 93-107, 2013

\section{Radon monitoring as a possible indicator of tectonic events}

V. I. Outkin et al.

\section{Title Page}

Abstract Introduction

Conclusions

Tables References

\section{Figures}

14

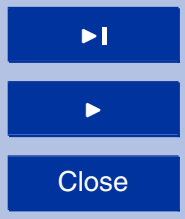

Back

Close

Printer-friendly Version

Interactive Discussion 
The impact of magnitude of earthquake is havoc both in terms of earthquake hazards and breaking of the causative earthquake souce rock with release of tremedous energy as evident from the 2001 Bhuj earthquake (Mw 7.6) (Mishra et al., 2008), and Sumatra - Andaman tsunamigenic earthquake (Mw 9.3) (Mishra et al., 2007a,b). Dur5 ing the earthquake making process, the radon bearing source rock under high stress condition tends to release the gas once the rock matrix started to disintegrate by loosening of the cohesive forces exists among the mineral assemblages of the rock mass when the strain builds up. The process of emanation of radon may be higher for the high asperity zone, which are generally capable to generate strong to great magnitude 10 earthquakes, while the zone of micro tremors $(M<4.0)$ may not be apt for emanating appreciable radon gas before the micro-tremors because of comparatively less competent source rocks that breaks under lesser stress regime in comparison to those of high asperity zones having high stress concentration (Dutta et al., 2012b). Such diagnostic behaviour of radon emanation during the earthquake making process may be used for earthquake forecast once assessment of the radon emission can be made through its continuous montoring. Concentration of radon in soil air (in array) hundredths of a percent. Thus, radon is an indicator of fluid movement (solutions) in the array or the soil. The radon as geochemical object that cannot claim to be the main "engine" of mountain masses, which, however may be addressed in future research through fabricating an appropriate model for better understanding of th role of radon as a plausible indicator of mountain masses related to the forecast of major tectonic events.

\section{Conclusions}

A method for measuring radon monitoring and aggregation function array speed conventionally named geodynamic monitoring (GDM) that can be used to solve the prob-

\section{ESDD}

4, 93-107, 2013

\section{Radon monitoring as a possible indicator of tectonic events}

V. I. Outkin et al.

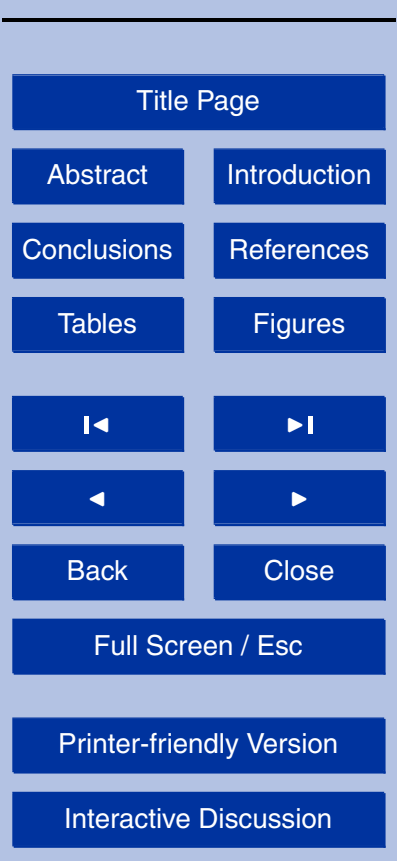
seismic monitoring data serves the main criteria for operational challenges of forecasting. Some sites suffer increase speed of migration of radon in the researched volume 
due to convective-dilatancy transport. Hence positioning information will be helpful in understanding behavior of the remote system. With the deepening of the research of instruments useful in radon data analysis and positioning technologies and methods have emerged, such as those based on the relative positioning of the deployment lo5 cation method based the absolute geographic information positioning method as well as the positioning method based on the UWB ultra wideband technology can be done. Positioning information used to report the location of the incident using wireless sensor nodes. Therefore, depending on the application characteristics and environmental conditions must select the appropriate positioning algorithm and technology, in order 10 to meet the user's specific application requirements.

\section{References}

Drury, S. A.: Image Interpretation in Geology, 2nd Edn., Chapman and Hall, London, 1993.

Dutta, P. K., Naskar, M. K., and Mishra, O. P.: Test of strain behavior model with Radon anomaly in earthquake prone zones, Himalayan Geol., 33, 23-28, 2012a.

15 Dutta, P. K., Naskar, M. K., and Mishra, O. P.: Test of strain behavior model with radon anomaly: A Bayesian probability approach, Scientific Research Publishing, Int. J. Geosci., 3, 126-132, doi:10.4236/ijg.2012.31015, 2012b.

Friedmann, H., Aric, K., Gutdeutsch, R., King, C. Y., Altay, C., and Sav, H.: Radon measurements for earthquake prediction along the North Anatolian Fault Zone: a progress report, Tectonophysics, 152, 209-214, 1988.

Hatuda, Z.: Radon content and its change in soil air near the ground surface. Memoirs of the College of Science, University of Kyoto, Series B, 20, 285-306, 1953.

Hirotaka, U., Moriuchi, H., Takemura, Y., Tsuchida, H., Fujii, I., and Nakamura, M.: Anomalously high radon discharge from the Atotsugawa fault prior to the western Nagano Prefecture earthquake (m 6.8) of September 14, 1984, Tectonophysics, 152, 147-152, 1988.

Igarashi, G., Saeki, S., Takahata, N., Sumikawa, K., Tasaka, S., Sasaki, Y., Takahashi, M., and Sano, Y.: Ground-water radon anomaly before the Kobe earthquake in Japan, Science, 269, 60-61, 1995.

\section{ESDD}

4, 93-107, 2013

\section{Radon monitoring as a possible indicator of tectonic events}

V. I. Outkin et al.

\section{Title Page}

Abstract Introduction

Conclusions References

Tables Figures
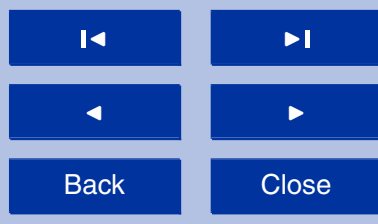

Back

Close

\section{Full Screen / Esc}

Printer-friendly Version

Interactive Discussion

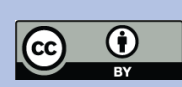


Imamura, G.: Report on the observed variation of the Tochiomata hot spring immediately before the Nagano earthquake of july 15, 1947, Kagaku, 11, 16-17, 1947.

Immè, G., La Delfa, S., Lo Nigro, S., Morelli, D., and Patanè, G.: Gas Radon emission related to geodynamic activity of Mt. Etna, Ann. Geophys., 48, 65-71, 2005,

$5 \quad$ http://www.ann-geophys.net/48/65/2005/.

Inceoz, M., Baykara, O., Aksoy, E., and Dogru, M.: Measurements of soil gas radon in active fault systems: a case study along the North and East Anatolian fault systems in Turkey, Radiat. Measure., 41, 349-353, 2006.

King, C.-Y.: Gas geochemistry applied to earthquake prediction: An overview, J. Geophys. Res., 91, 12269-12281, 1986.

King, C.-Y., Walkingstick, C., and Basler, D.: Radon in soil gas along active faults in central California, in: Field Studies of Radon In Rocks, Soils and Water, edited by: Gundersen, C. S. and Wanty, R. B., US Geol. Sur. Open File Report, 77-143, 1993.

Mishra, O. P., Chakrabortty, G. K., Singh, O. P., Kayal, J. R., and Ghosh, D.: Aftershock investi15 gation in the Andaman-Nicobar Islands: An antidote to public panic, Seismol. Res. Lett., 78, 591-600, 2007a.

Mishra, O. P., Kayal, J. R., Chakrabortty, G. K., Singh, O. P., and Ghosh, D.: Aftershock investigation in Andaman-Nicobar of the 26 December 2004 earthquake (Mw 9.3) and its seismotectonic implications, Bull. Seismol. Soc. Am., 97, S71-S85, 2007b.

20 Mishra, O. P., Zhao, D., and Wang, Z.: The genesis of the 2001 Bhuj,India, earthquake (Mw 7.6): A Puzzle for Peninsular India, J. Indian Minerals, 61/62, 149-170, 2008.

Morelli, D., Immè, G., Altamore, I., Cammisa, S., Giammanco, S., La Delfa, S., Mangano, G., Neri, M., and Patanè, G.: Radioactivity measurements in volcano-tectonic area for geodynamic process study, EPJ Web of Conferences, 24, 05009, doi:10.1016/j.nima.2011.01.172, 252012.

Outkin, V. I.: Spatio-temporal monitoring of radon and the problem of the medium-term forecast of tectonic earthquakes, Ural geophysical journal, no. 1, IGF UB RAS, Yekaterinburg, 101106, 2000.

Outkin, V. I. and Kozlova, I. A.: Massif was straining the reflection in the dynamics condition radon field, XXV General Assembly EGS, Nica, France, 1356-1358, 2000.

Outkin, V. I. and Yurkov, A. K.: Radon and tectonic earthquakes problem, Vulcanol. Seismol., 4, 84-92, 1997a.

ESDD

4, 93-107, 2013

\section{Radon monitoring as a possible indicator of tectonic events}

V. I. Outkin et al.

\section{Title Page}

Abstract

Introduction

Conclusions

References

Tables

Figures

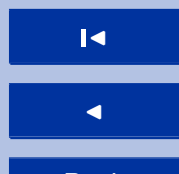

Back

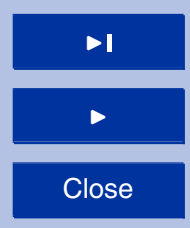

Full Screen / Esc

Printer-friendly Version

Interactive Discussion

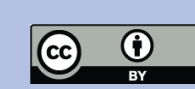


Outkin, V. I. and Yurkov, A. K.: Reflection seismic events in the radon exhalation Geophysics, m, EAGO, 6, 50-56, 1997b.

Outkin, V. I., Kozlova, I. A., and Yurkov, A. K.: Radon as an indicator of stress state array Melinikovskie read the book perm, Mining Institute UB RAS, Russia, 79-82, 1999.

5 Outkin, V. I., Mamyrov, E., Kang, M., Krivasheev, S. V., Yurkov, A. K., Kosyakin, I. I., and Shishkanov, A. N.: Radon Monitoring study of preparation process of tectonic earthquake on the Northern Tien Shan, Phys. Earth, 9, 145-155, 2006.

Outkin, V. I., Yurkov, A. K., Klimshin, A. V., and Kozlova, I. A.: Geodynmic monitoring in real times, AGU 2011, USGS, S-Franc., Institute of Geophysics, AGU, 1203407, 2011.

10 Rastogi, B. K., Chadha, R. K., and Raju, I. P.: Seismicity near Bhatsa reservoir, Maharashtra, India, Phys. Earth Planet. Inter., 44, 179-199, 1986.

Rogozhin, E. A.: History intensified seismogenerating structures of Northern Eurasia in the Holocene, Rep. RAS, Moscow UIPE, 370, 390-392, 2002.

Sarson, G. R. and Jones, C. A.: A convection driven geodynamo reversal model, Phys. Earth 15 Planet. Inter., 111, 3-20, 1999.

Tsukuda, T.: Radon-gas Monitoring by Gamma-ray Measurements on the Ground for Detecting Crustal Activity Changes Preliminary Study by Repeat Survey Method, Bull. Earthq. Res. Inst., 83, 227-241, 2008.

Ulomov, V. I., Zakharovc, A. I., and Ulomova, N. V. :Tashkent earthquake of April 26, 1966, and its aftershocks, Akad Nauk SSSR, Geophysic, 177, 567-570, 1967.

Walia, V., Virk, H. S., and Bajwa, B. S.: Radon Precursory Signals for Some Earthquakes of Magnitude > 5 Occurred in N-W Himalaya: An Overview, Pure Appl. Geophys., 163, 711721, 2006.

\section{ESDD}

4, 93-107, 2013

\section{Radon monitoring as a possible indicator of tectonic events}

V. I. Outkin et al.

\section{Title Page}

Abstract

Introduction

Conclusions

References

Tables

Figures
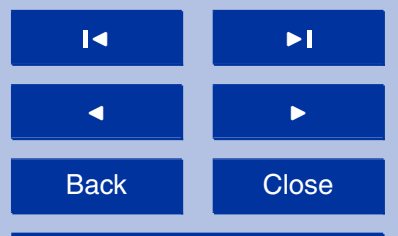

Back

Close

Full Screen / Esc

Printer-friendly Version

Interactive Discussion

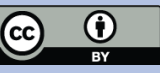



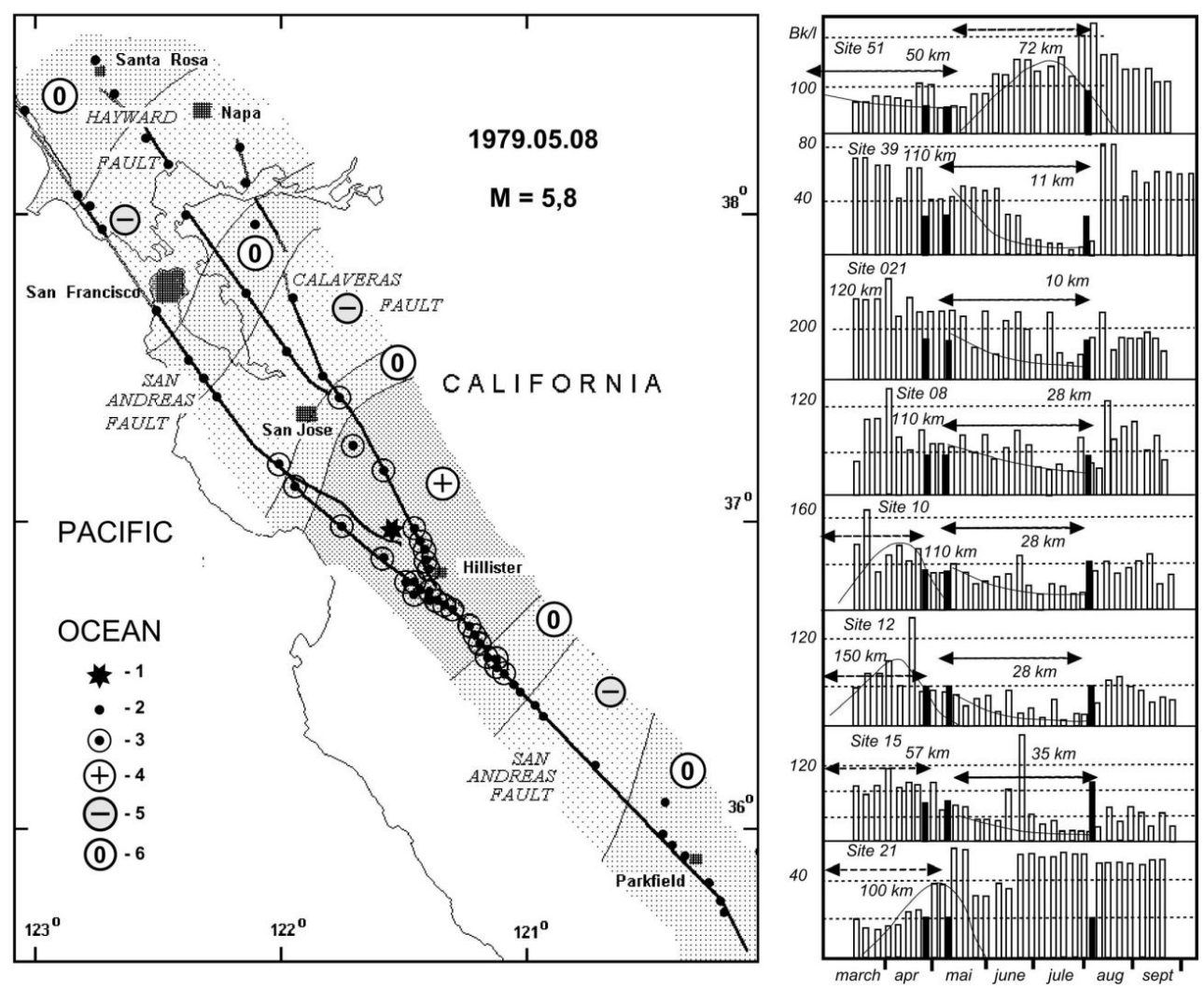

ESDD

4, 93-107, 2013

\section{Radon monitoring as a possible indicator of tectonic events}

V. I. Outkin et al.

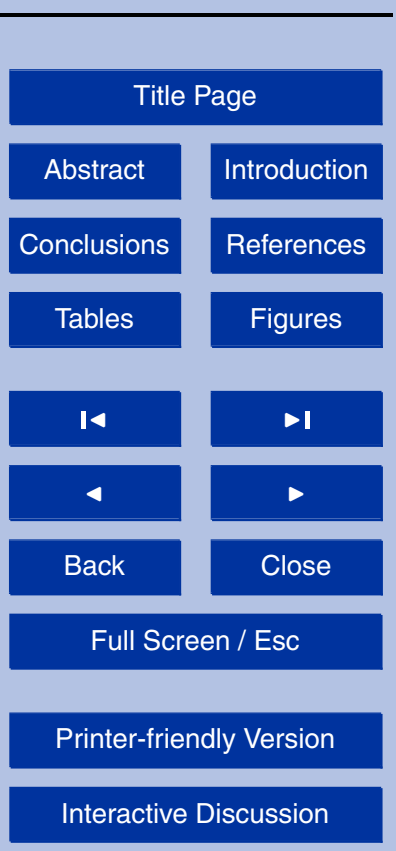
zone array, 6 - "neutral" zone (a zone with no visible signs of compression or tension). 


\section{ESDD}

4, 93-107, 2013

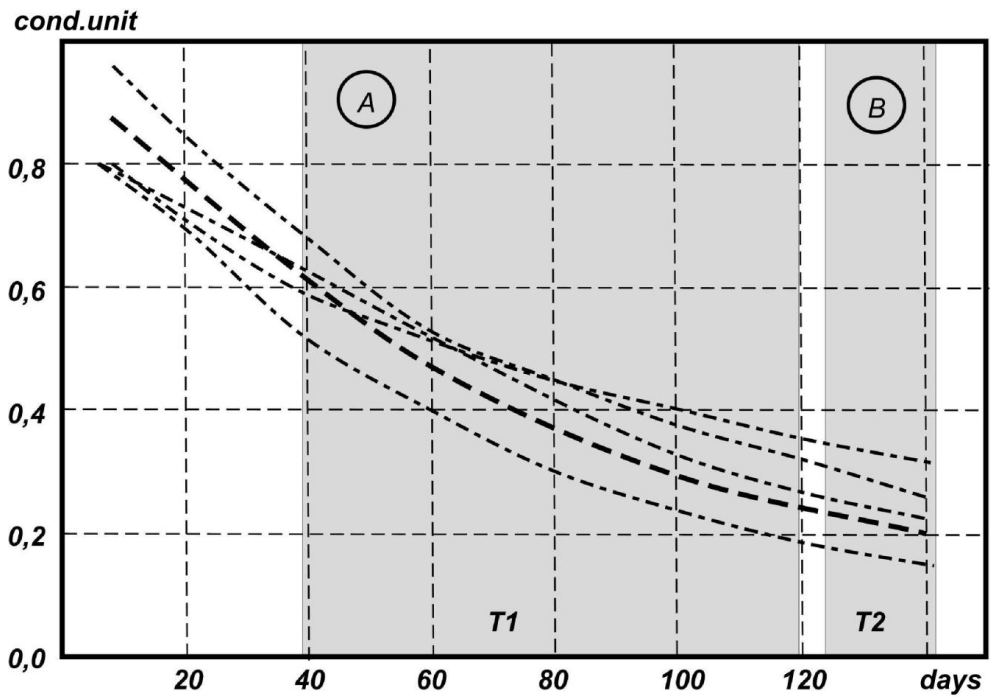

\section{Radon monitoring as} a possible indicator of tectonic events

V. I. Outkin et al.

\section{Title Page}

Abstract

Introduction

Conclusions

References

Tables

Figures
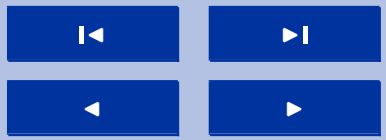

Back

Close

of earthquake preparation $(B)$ - time T2 - the zone of destruction of the array (tectonic earthquake).

\section{Full Screen / Esc}

Printer-friendly Version

Interactive Discussion 


\section{ESDD}

4, 93-107, 2013

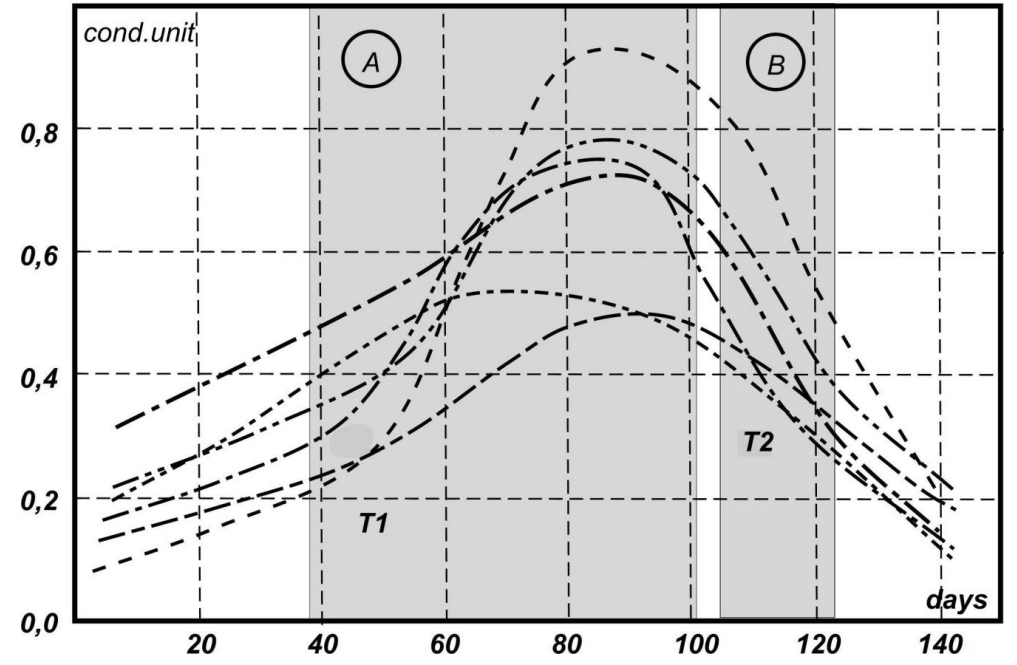

\section{Radon monitoring as a possible indicator of tectonic events}

V. I. Outkin et al.

\section{Title Page}

Abstract

Introduction

Conclusions

References

Tables

Figures
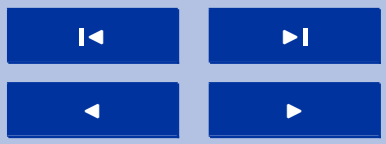

Back

Close

- the zone of earthquake preparation, T2 - the time zone of destruction of the array (tectonic earthquake).

Printer-friendly Version

Interactive Discussion 